\title{
MJN THE JOURNEY OF PEDESTRIAN VICTIMS TOWARDS RECOVERY
}

\author{
Norie Jane G. Maxino', Emiliano lan B. Suson II* \\ ${ }^{1}$ Vicente Sotto Memorial Medical Center, Philippines \\ ${ }^{2}$ Cebu Normal University, Philippines \\ *Corresponding Author’s Email: susonei@cnu.edu.ph
}

\begin{abstract}
Road crashes are leading causes of traumatic injury in the world and the pedestrians are always the most vulnerable victims. Motor Vehicular Accidents (MVAs) have been found to be one of the causes of posttraumatic stress disorder and acute stress disorders. This study utilized the descriptive (Husserlian) phenomenology by Edmund Husserl to explore the meaning of a person's experience. Five (5) male and 5 female pedestrians who encountered a motor vehicular accident within the localities of Cebu participated in the study until data saturation was reached. After consent had been signed a recorded interview was done to explore the experience of these informants. Subsequently, transcriptions were made, the data were then analyzed, compared and condensed to draw a common ground. Using Colaizzi's seven steps in processing phenomenological data analysis, three themes emerged from the 28 significant statements of the informants. The first theme, "Pull Over", talks about the trauma that caused a standstill. "Caution", the second theme, refers to proceeding but with caution; and lastly, the third theme, "Proceed", refers to finally moving on with confidence. The results of this study would help to assist reshaping the driver's mindset when driving and additional measures may be implemented to ensure road safety such as educating drivers of the possibilities of the events that might occur when they ignore the risks of driving.
\end{abstract}

Keywords: Motor Vehicular Accident, Traumatic Experience, Pedestrian, Lived Experience

\section{INTRODUCTION}

In the current Philippine health system, nurses are considered the first line of defense in emergency departments (ED). It is evidently noticeable that they are being beset with the dilemma in search for quality service to all sorts of patients who sought their services every day. Vehicular accidents are one of the highest numbers of cases being served in the ED. The Department of Health by its National Electronic Injury Surveillance System reported that in 2010 alone, a total of 3,077 injuries were related to vehicular accident. In addition to this report, $41.2 \%$ were accounted to collision accidents accounted and unsurprisingly, more males were involved than females with $76 \%$ and $24 \%$ distribution respectively (DOH, 2013). They are the most frequent, directly experienced trauma for men and the second most frequent trauma for women (Galovski $\&$ Veazey, 2016).

Despite the enormous effort made by nurses to make a vast difference in the delivery of health care, the use of conventional health practices and approaches in caring the victims of motor vehicular accidents (MVA) remains a practice. This unintentional miscalculation of the first line responders in the Emergency Department (ED) in caring for MVA victims, specifically the innocent and vulnerable pedestrians, is considered a huge gap between the target quality service and the personal satisfaction felt by the ED nurses. Pedestrians who succumbed to vehicular accident tend to play the weak and distrustful role challenging the nurses (in particular) in their undying effort to preserve the dignity of each patient. Pedestrian is defined as someone or any individual whether strolling, trekking, or jogging on foot, along a road and also person on foot or using roller skates, skateboards, scooters, and wheelchairs in an urban area. (Merriam Webster, 2017).

But nurses seemed to set aside the essentiality of addressing the emotional aspect of a pedestrian following a Motor Vehicular Accident (MVA), and merely focus on the physical symptoms, instead. Unknowingly, the 
numbers of vehicular victims that are seeking medical attention at key hospitals in the Philippines are soaring high every single year despite the government's attempt to fully implement the long-standing traffic rules, laws and regulation by way of Republic Act 4136. In addition to this, the understaffing and congestion problem of major DOH run hospitals somehow contributed to the wide gap in health care delivery systems because health care providers $(\mathrm{HCP})$ are evidently out-numbered in terms of patient-nurse ratio.

Moreover, the nurses' role towards their patients must be holistic both physical and psychological. The MVA survivor would experience a blow in his response to discontinuity of being well because this accident would have a profound impact on him that might alter his life perspectives and response to illness. Tull (2016) reported that anybody who had been in a vehicular accident is prone to develop post-traumatic stress disorder (PTSD). About $50 \%$ of them who need medical treatment develop PTSD. This sudden detour from health continuum cripples the survivors at the $\mathrm{ED}$, the inclusion of the psychological aspect in the formulation of quality standards of care, specifically tailored to vehicular accident victims, must suffice.

According to the World Health Organization (WHO) in 2015, road crashes are one of the leading causes of traumatic injury. Furthermore, 1.25 million people died worldwide from road accidents yearly, and virtually half of those deaths are "susceptible" road users like the pedestrians, cyclists, and motorcyclists. Data also added that $22 \%$ of the world's road traffic deaths were attributed to pedestrians and the highest incidence of road fatalities were from the third world countries. A study reported around 184 car-pedestrian accidents in China, as pedestrians were the most frequently involved in pedestrian-vehicle accident, making them the most common and most vulnerable road users (Hui et al., 2010).

With the occurrence of this overwhelming information, the primary intention of the nurse researchers is focused mainly on the formulation of holistic nursing approach that would include the exploration of motor vehicular accident in terms of the survivors' adaptation to stress and interruption of being well. The researchers investigated the post trauma behavioral changes that could directly or indirectly affect the victim's response to care regimen. The need of individualized nursing care focuses on the disabling lived experiences, the deepening of the understanding of their behavior, and the utilization of tested strategies applicable to the crisis situation.

\section{Objective of the Study}

This study is aimed to explore the lived experiences of pedestrian victims of vehicular accident in Cebu.

\section{Significance of the Study}

In understanding the behavioral modification of clients who have been in a vehicular accident and establishing a worthwhile trusting relationship between the caregivers and their clientele, the community and the institution, an adaptation of standardized plan of care that would include the mental aspect that need to be embraced by all health institutions, by medical and nursing schools, and other allied professions.

Pedestrian Victims. In the formulation of holistic nursing approach, the inclusion of the exploration of the end-product of being in a motor vehicular accident in terms of the survivors' response and adaptation to stress is believed to play a major role in helping them deal with the consequences of the crash.

Researchers. By understanding the lived experiences of the informants, this study will further broaden up the minds and hearts of the researchers to understand the victims' perceptions towards the injury and their understanding of the accident in a hope of formulating an effective and holistic plan of care, as well as health teachings that are highly specialized to pedestrians who suffered from MVAs.

Nurses. As change agents, nurses could utilize this study to promote better, advanced, and more precise behavioral modification strategies among these victims.

Community and law enforcers. This study will likewise benefit the people in the community and the law enforcers to raise awareness of the debilitating effects of vehicular accident so that traffic rules and regulations will be strictly followed, and other modifiable risks will be eradicated.

Emergency Management Technician. This study will also benefit nurses who are deployed outside the four corners of hospitals including the emergency medical responders in the hope that this will drive them to search for more relevant and highly effective prehospital care to prevent further complications from injury and promote well-being specially during mass 
casualty and other major catastrophe.

\section{Review of Literatures}

Survivors of MVAs often experienced emotional distress and mental health difficulties that might play a major role towards recovery of health. With the fastrising numbers of individuals who owned cars and motorcycles in the Philippines, not to mention the continuous improvement in the road transportation industry, comes a significant climb in reported road tragedies. According to the Centers for Disease Control and Prevention, traffic crashes claimed 5,376 lives and 70,000 people were reported injured. It further claimed that one crash-related pedestrian death occurs in every 1.6 hours in the US, citing an approximately 129,000 pedestrians were attended in emergency departments for slight physical injuries (CDC, 2017).

A similar study aimed to identify the occurrence of PTSD and post-traumatic stress symptoms (PTSS) among children and adolescents who suffered injuries during road accidents. The study reported several associations with PTSS and PTSD including perceived threat and high levels of distress, anxiety symptoms mostly among female. The severity of injury was associated to the number of symptoms and the types of accident, age, and socioeconomic status had no direct relationship to its development. Therefore, any child after a road accident are vulnerable in developing disorder not just those with profound severity. Trauma care should be inclusive of identification and prevention of traumatic responses so that the possibility of associated psychological consequences would be minimized (Olofsson, Bunketorp \& Andersson, 2008).

According to the study, children after road traffic accidents (RTAs) may undergo major and long-standing mental health issues that need early psychological interference. In addition, this study showed a valuable effect of providing early psychological intervention to preadolescent children post RTA for their recovery. It has been recommended that further research to tailor an approach of care to early stage of RTAs specific to age might be more beneficial (Zehnder, Meuli \& Landolt, 2010).

Another related study assessed the health-related quality of life (HRQOL) and its impact of PTSS among injured children and adolescents following a road accident. About $16 \%$ percent of children examined manifested moderate to severe PTSS on HRQOL in 1- month time, while $17.6 \%$ or 12 children in 1 year. During the period of first months, patients reported decreased motor functioning and independence and destructions in some parts of emotional functioning. After a year, all scope of HRQOL was within or above the normal range. Indeed, there was an evidence that the return of the injured children to their pre-injury stage not only depended on optimum medical attention but also on the awareness and timely interventions regarding PTSS because this have a long term negative influence in these population after a vehicular accident (Landot et al., 2009).

A research study reported the incidence and prediction of psychiatric morbidity after a motor vehicle accident in Japan. The Tachikawa Cohort of Motor Vehicle Accident Study was alarming and conclusive because a great number of patients manifested major psychiatric illnesses like depression, post-traumatic stress disorder (PTSD), alcohol dependence, obsessivecompulsive disorder, agoraphobia, and social phobia at the 4-6 weeks follow up. Some psychiatric morbidity was also predicted by a sense of life threat, elevated heart rate and higher Impact of Event Scale-Revised Intrusion Subscale score (Yutaka et al., 2008).

The results of a study conducted in France on patients over 15 years of age that had experienced road traffic accident showed that while they were receiving care in a hospital, psychological distress was evident after they answered a self-administered postal questionnaire. Factors associated with PTSD were severity of the initial injury, amnesia post-trauma, the sense unaccountability for the misfortune and pain that persisted 6 months after it (Chossegros et al., 2011).

The physical pain and the debilitating experience were crucial to all vehicular accidents victims but claiming compensations might end up more stressful as well. Another study dealt with the imperative need to review policy and legislation pertaining to claims. Citing it as an additional burden and stress to the victims. This could influence their perception towards coping from the experienced phenomenon and their course of recovery (Murgatroyd, Cameron \& Harris, 2011).

Another study mentioned independent predictors for both acute stress disorder (ASD) and PTSD. Parents have greater chances of developing psychological imbalance whenever their children are being subjected to trauma and unsurprisingly, their responses were consistently associated with post trauma psychological 
recovery. Pre and peri-trauma exposures and child's perception to pain and life threat, and severity were the cited as independent predictors. Dissociative symptoms and manifestations of re-experiencing, avoidance, and hyperarousal were positively manifested by the parents within barely a month of trauma (Adams, Fleisher \& Winston, 2009).

Behavioral changes manifested by pedestrian victims, do not usually vary since majority, if not all, have gone through the same stages in responding and adapting to stressors and disequilibrium. The experiences of fear, apprehensions, hostilities, remorse towards the disruption of the normal everyday lives of these victims appeared inevitable and their method of response to this sudden transition are quite the same in pattern (Alnaqbi, 2013).

Pedestrian-vehicle clash is common in the road with high mortality rate despite the government's much paid attention and effort to at least minimize the number of incidences. After analyzing the lived experiences of pedestrian victims of vehicular accident, relation to the age, gender, civil status, mental status, occupation and educational attainment or profession, the researchers could establish a concrete plan of holistic care applicable to this group that would include psychological care in the emergency department settings to minimize its debilitating effect.

Plan of care like establishing a trusting relationship between the caregiver and the care seekers should be the primary approach to facilitate the start of therapy. The exploration of feelings, inner thoughts, disabling memories and verbalizations of ill feelings towards the tragedy should be handled with so much sensitivity, as well. Early identification of psychological impairment manifested by the patients at the ED is crucial for health care providers in providing basis in the formulation of plan of care. As an emergency nurse, gaining broader insights and knowledge regarding the disease process, will equip her with the tools he needed to address this concern.

In support to this noble endeavor and to unveil a more effective and efficient nursing practice, this study is anchored to Betty Neuman's Health Care System Model. The system is designed to use unique approach in responding to stressors depending on the prevention modality that they adapt.

\section{METHODOLOGY}

A phenomenological research design was used since it aimed to reveal the true meaning of the lived experiences of pedestrians with a motor vehicular accident. The phenomenological approach best develops the information gathered since its goal is to observe, describe, and document accurately the lived experiences of the individuals in relation to the research study. As defined by Grbich (2013), phenomenology is used as an approach to explore the hidden meanings as well as the importance of the experience. The data for analysis is primarily collected through stories, interviews, and/or observations of the respondents to gain understanding of the meaning of their lived experiences. Building trust to the interviewers plays a vital role in this type of research design since it would be a great help to let the respondents talk freely to be able to gather more accurate and specific data (Balls, 2009).

The descriptive Husserlian phenomenology by Edmund Husserl was also anchored in this study because it is thought to be the most appropriate method that could address the purpose of the research topic which is to explore the lived experiences of pedestrians who were victims of MVAs with the essence of pure. Consciousness (Christensen, Welch \& Barr, 2017). This process requires the researchers to strip off all preceding knowledge related to the phenomenon in order to acquire essential lived experiences from the informants. Experiences of phenomenon as perceived by human consciousness should be greatly valued as objects of scientific study. Moreover, this method of phenomenological investigation aimed to synthesize the meaning, the purpose, and the effect of experiences, rather than measuring those (Lopez $\&$ Willis, 2004).

The research study was conducted within the localities of Metro Cebu to known pedestrians who have experienced injuries related to motor vehicular accident whether admitted or sought consultation in a tertiary government hospital in Cebu. Cebu is chosen by the researchers since road accidents is among the top ten causes of mortality in 2015 and was confirmed by the data reported by the Cebu City Traffic Office that six accidents happened every single day. The research study made use of purposive sampling wherein a selection of non-probability sample will be based on the target population's characteristics and the study's objective. The opinion of the smaller group of people could be used to represent a large population, as a whole (Crossman, 2017). There were 10 informants interviewed by the researchers before data saturation had been reached 
since the description of the lived experience was different from the rest of the informants. Data saturation is reached when there is enough information to replicate the study. All 10 informants five males and five females respectively, experienced trauma right after the accident. The similar findings of the respondents were the basis to reach data saturation and the lack of any new emerging data is evidence that saturation has been achieved (O'Reilly \& Parker, 2012; Walker, 2012).

The instrument utilized for the data gathering was a semi-structured key informant interview guide to explore the lived experience of the victims of the vehicular accidents. There were also follow-up questions for the informants to gain and validate insight. There was also a pilot study conducted on two selected informants to evaluate viability, time, expenditure and adverse events to pave way to a more valid, substantial, credible and dependable study design before a full-size research will be conducted. The selection and the chronology of questions were finalized and considered appropriate after it was repeatedly examined and scrutinized with full sensitivity to the informants' feelings, level of understanding and comprehension and environmental factors, as well.

\section{Data Gathering Procedure}

For the data gathering procedure to become credible, trustworthy, dependable and reliable, the researchers required herself to be liberated from her own knowledge of the research topic by putting aside her own beliefs, insights and views prior to and throughout the phenomenological investigation. Bracketing in the first part of data gathering in most qualitative research is very important in verifying the validity of the research output by diminishing possible contamination in the research process from the researchers' presumption, prejudice and biases (Tufford \& Newman, 2010).

Upon approval of the proposed study by the Vicente Sotto Memorial Medical Center Ethics and Review Committee, the researchers went to the research locale to look for individuals who qualified in the inclusion criteria set. The identified ten informants were personally asked for their willingness to participate followed by a thorough explanation of the significance, scope, process of the study and acquired consent regarding the utilization of an audio recording. A signed informed consent was prepared by the researchers and the informants were provided ample time to read through it prior to affixing their signatures. Before the interview, reassurance of withholding their names to ensure privacy and confidentiality was also stressed. After an agreement had been met, an interview schedule was set in consideration to the informant's comfort, preference and convenience.

The researchers did the data documentation and preserved the audio recording of the interview. After all interviews were completed, the researchers' transcription of the recorded interview was compared and condensed to draw a common ground, accumulate case knowledge, interpret and establish trends and thus yield new knowledge. The study utilized Colaizzi's strategy of descriptive phenomenological data analysis to attain a wide-based support in digging up, organizing, and evaluating data as narrated by each of the informants. In the analysis of the data gathered, Collaizi's Process for phenomenological data analysis, as cited in Speziale \& Carpenter (2007), was utilized in the extraction, organization, and analysis of the narrative dataset. In relation to Collaizi's phenomenology data analysis model, the following activities were observerd: 1 . Transcribing the interview in verbatim; 2 . Reading and re-reading the transcribed-word-for-word interviews to make sense of them and will acquire a feel for each description; 3. Extracting the significant statements, which pertain directly to the proposed phenomenon, from the descriptions; 4. Formulating meaning after analyzing each statement; 5 . Organizing the formulated meanings into clusters, which allows themes to emerge; 6. Integrating themes into an exhaustive description. Making concise statement of the exhaustive description to bring out the fundamental statement of identification; and, 7. Presenting concise statement of the exhaustive description to the original participants in order to verify the statement. In the application of Colaizzi's seven steps in processing phenomenological data analysis the researchers were able to elicit exhaustive description of the informant's experienced phenomenon (Shosha, 2012). Before the collection of data, the researchers secured clearance from the Ethics Review Committee from a reputable government hospital. Emphasis was given on the interview to maintain the informants' statement with no contamination due to personal biases and knowledge prior to the interview. The researchers, on a lighter note, gave full involvement in allowing the participants to decide and describe the phenomenon to attain an interpretation of its own.

The data collection phase of the study was an interview phase of the researchers to the informants and 
review of data collected. The researcher drew a significant statements, thematic analysis and findings. To validate the veracity of the interpretation from their actual experiences, the researchers went back to ask the informants to verify if the thematic clusters written in Cebuano were exhaustive description of their experiences.

\section{RESULTS AND DISCUSSION}

\section{Profile of the Informants}

The informants involved in the study were five male and five female adults who were pedestrian victims of a motor vehicular accident. Their ages ranged from 18 - 60 years old. Furthermore, to add confidentiality to the respondents, the researchers has composed a pseudonym for the respondents and presented them chronologically according to gender and age.

Luna. She is a 60-year-old grandmother who is living with her daughter in a highly progressive town next to Mandaue city. She usually starts her day as early as five in the morning going to the market to buy goods to be sold at her small store outside her home. The driver of a luxury car bumped over her causing her to be thrown few meters away from the road with the loss of consciousness. She is the $5^{\text {th }}$ among 9 children who said that being obedient and responsible were the key to the success of her family. She was widowed at the age of 45 but never had a second thought of remarrying for her to focus on her 3 children.

Tetchy. She is a 60 -year-old retired public school teacher who bursts into tears while relating her very traumatic experience inside her home in Labangon, Cebu city. Despite being left home alone by her husband who has been working overseas since their children were still in elementary level at school and children who are now having a home of their own, she was able to balance life almost in perfection. Her strong faith with the Lord was also remarkable as she always holds on to a bible verse that says, "God has a plan for you, plan to prosper and not harm you".

Sheer. A 47-year-old street sweeper for almost a decade, a single mom of two and a responsible daughter to a physically challenged father after a car accident. This happy go lucky lady can define life in the simplest ways because she believed that there should be no reason for people to worry if they will only wish for a simple, uncomplicated one. The fathers of her children remained her friends and so with their wives. Sheer wanted to stay optimistic as always to get rid from illness and frustrations. Because she was not able to finish elementary school, she could hardly find a decent job. Street sweeping is the only job she knows. This job helped her feed her father, children, and grandchildren.

Maria. She has gone through so much in her life and yet ended up victorious. But there is hardly any traces of hardship and struggle because she never carries extra luggage with her. Her eldest son is now in his senior years in high school while the other children are still in elementary. At the age of twelve, Maria already knew how hard life was. Her mother left them at a young aged and she was forced to make both ends meet to survive. Currently, she is working in a furniture factory heading sales and promotion. Her perseverance helped her to finish college by being a working student.

Cindy. She is a 34-year-old cigarette vendor who has no house to call her own after losing it in a fire several years ago. Up to this date, she is living with her relatives in the squatter's area who are constantly threatened by demolition. At one glimpse she might seems to be sturdy and tough, but she had a surprising sense of spirituality. She has also a strong faith and thought that God must have given her several lives for some purpose she is still figuring it out. Despite everything, she still thinks her life is on the busy street and nowhere else. She believed that one cannot escape death, if it is time, no one can simply evade it.

Bill. He described himself as a "moderate alcohol drinker" who actually enjoyed three to five glasses of "tuba" (coconut wine) every day for him to be energized. $\mathrm{He}$ is a regular delivery truck boy even at his age of 59 because according to him, this the only job he could find for not going to school. He lived in a small temporary shelter near the Cebu pier and has been in the city for almost four decades after he left his province in search for better opportunities. He has learned about life in the hard way and this made him the person he is today. With the huge muscles and stamina, carrying sacks of rice, goods, and vegetables is never tedious for him. His motivation to carry on heavy loads is to survive and remain alive.

Chad. He is a sporty, health conscious, physically fit 52-year-old lad who have been cycling for over a decade. He came from a wealthy Chinese clan in Bohol. Up to this date, he is still single but has a son from a former girlfriend. On a sad note, the person who happened to hit him was a medical practitioner who, 
according to him, was not gracious enough to extend assistance. He had learned his lessons well from that incident but never set aside the urge to seek justice for what happened. He wanted the government to promote road worthiness among pedestrians including cyclist, joggers and skaters, runners to name a few.

Mar. This 39-year-old hotel employee is a loving husband and a dependable father, as well. He takes pride of his achievement, his family and his loyalty to his work. He married at an early age but was able to finish college and was able to provide his family's needs despite these circumstances. The accident, that caused him minor injury, brought him some good news too, since probably out of the assailant's noble intention, he was offered a part-time job at one of his bakeries in the city. He welcomed it knowing that this would ease the financial constraints his family have been facing.

Herbert. A call center agent, a nurse by profession and a responsible husband is the 27-year-old pedestrian victim of a motor vehicular accident who hailed from a well to do family. He said that no matter how you strive hard to keep his family safe, there are some irresponsible and reckless people who would come along to break the chain. He strongly believed that Filipinos should learn road discipline and responsible driving is the key to eradicating road death and injuries. The greatest thing he has ever achieved is raising his family on his own. Since childhood, he valued independence, hard work, ingenuity, perseverance, resilience and pride without any display of arrogance.

Leo. The most heartbreaking story ever told was the one from the 19-year-old Leo. He was still in eleventh grade when a pedestrian tragedy occurred. His mother asked him to run an errand alongside his uncle, who was severely hit and died few days after the incident. With a grateful heart, he wanted to use this second life to serve the Lord and become a priest if God will anoint him. Since childhood, he has been picked by playmates who often call him names because they perceived him as a man with the soft side. Due to poverty, he helped his mom raise pigs that will be sold when they reach the desired size. He sells coconut candy to his classmates and does carwash on Saturdays. His family is very happy and felt blessed to have him as a child who never think of himself but of his loved ones.

\section{Thematic Analysis}

After the analysis of the data utilizing Collaizi's method, three themes emerged from the shared experiences of the participants being involved in the study.

The first theme, "Pull Over" talks about the fear they felt right after the accident which they did not easily overcome. The victims did not resume for a while their usual daily routines and tried to seek refuge. As a result, fear, anxiety and depression occurred that prevented them to resume a normal life. "Caution", the second theme, refers to the time of gradual regaining of strength and confidence to go back to the streets again but with caution and assistance from their significant others. In this stage, the essentiality of focusing on what is behind that tunnel, and choosing the right route, the right time or the right attitude when using the pedestrian were given too much weight. They were resuming their usual pattern of activity gradually like using the pedestrians, walking or jogging with too much emphasis on safety and security. Moving on and moving forward with their lives is what the third theme "Proceed" is all about. Respondents currently have now full control and desensitization over the situation. While it is true that accidents are inevitable, disastrous and life changing, they have come to a great realization that they must fight back fear and anxiety to continue their journey. Life is like a gamble, if you do not win, you lose but one should not pass their papers that easy.

\section{Theme 1 "Pull Over"}

This is the stage where there is a temporary stoppage from their usual routine. Encountering road accident is equally traumatizing and nerve wrecking that it could cause a tremendous shift of one's natural course of life, anxiety, fear and in some worst cases, depression. In some instance, where psychological wellbeing is defined, and physical injuries are more pronounced, people cope by hiding in their shell and refusing to resume their normal lives.

\section{Luna expressed her fear}

"Pwerte nako kalisang kay wala na gyud nako malihok ang ako walang bukton. Hubag kayo." (I could not move my left forearm. It was very swollen). "Nahadlok ko uy. Abi nako patay nako. Mahadlok na gud ko mangumpra. Kakaon ko ug tagam" (I was scared. I thought I already died. I was scared to go to the market. I have learned my lesson).

"Di kabayran ug sapi ang kakuyaw ug kahasol. Usa ko ka buwan wa nanilhig kay nagpaayo", as verbalized by Sheer. ("No amount of money can pay the fear and 
hassle. I stopped sweeping for a month for me to recuperate.")

Maria's account of the incident was horrifying as she said,

"Taud taud gyud mi nga nagpangurog og tabok sa kalsada. Magbalikbalik og flash sa imo mind. Manglimbawt gud ako mga balahibo" (I feared crossing the street for quiet sometime. It kept on flashing in my mind. I had goosebumps.")

According to Herbert,

"Mawala man ang scar pero ang imong emotion murag dugay dugay pa. (The scar might be erased but the emotion will linger.") He then further testified, "Mura naman sad mi ug paranoid kay nagsige na lang mi ug panglingi, dali makurat". ("We were paranoid because we kept on looking back, we easily get startled.")

As Mar verbalized his recollection of the trauma he had gone through,

"At first, dili ko mulakaw na mag inusara." ("At first, I refused to go out alone")

Leo remembered that after the incident,

"Usahay magdamgo ko, mukalit ra ko ug siyagit. Kaundangon ko ug skewla." ("Sometimes I dreamt I suddenly screamed. I almost stopped schooling.")

Chad said in one of his recollection:

"Undang bike bike, pahuway kadiyot sa amo probinsiya, ("I stopped going biking, rested for a while in my province.")

Collectively, though the emotional trauma was more prominent, vehicular accident's physical pain had also caused a standstill to the responder's lives. After a traumatic experience, the person who lived through the trauma may feel paralyzed, lifeless, as if there is no energy or will in them.

Cindy stopped selling in the streets. Her testimony,

"Mga duha ka semana hapit man gyud to uy. Nia ay wa pa kaayo maulii akong kamot, bag o pa gitangtangan sa semento. (I think that was almost two weeks. My arm has not yet fully recovered from the injury, the cast has just been removed recently".)

This man's reaction to his accident was almost the same with Cindy. Bill recounted,
"Nasakitan ko pero nahasol pud ko kay pila ko kabuwan na wala ka pangarga kay injured man." ("It was painful, but I also stopped working as a laborer for few months because of my injuries".)

Because of Techy's age, both the physical and emotional trauma stopped her from resuming her daily routine. She vented out:

"Nabun-og ako pikas bahin sa body, nagaras, na samad ug nalipong ko. Dugay dugay sad ko ug tambal sa trauma. Balay lang ko permi." ('Half of my body was bruised, scratched, lacerated and I felt dizzy. It took me longer to heal the trauma. I just stayed at home".)

The accident caused the informants to stop their usual activities because of the physical pain and emotional trauma they have been through. They had indulged themselves with other activities in order to alleviate the anxiety and pain in a hope to get back on track soon. From a shamanic perspective, it is the stealing of the life force from the victim that creates the sensation of lifelessness. From a psychological perspective, the shattering of the person's well-being creates a schism in their psyche that renders them temporarily powerless (Berry, 2013).

\section{Theme 2 "Caution"}

The informants after they have learned the hazard of the road they were slowly starting to play the game of chance again fully equipped with the tool of preparedness.

As human beings who have succumbed to physical and emotional trauma, they started to learn the effects of the unpredictable nature of their experienced phenomenon and wanted to take the risk again. As they have seen the incident in different perspectives, the courage to take the first step on the road was always crucial but left them with less choice.

A cyclist's view on what happened to him was remarkable. The excruciating pain taught Chad a big lesson:

"Na dili na gyud mukumpyansa, kun maglakaw adto sa safe side sa sud sa gutter para di maigo sa mga sakyanan." (I should not be confident, when walking, stay on the safer side inside the gutter so that no car can hit me.")

On the other hand, Mar had also his resolution,

"Kun maglakaw ka sa kalsada, adto sa side na imo makit-an ang sakyan na mopadulong nimo para di ka 
ma blind." (When walking on the street, you should be on the side that all approaching vehicles are visible so you won't get blinded.")

According to the 60-year-old Luna,

"Di na gyud ta maglahus lahus. Lingi, lingi gyud dapat." (We should not cross right away. You must keep on looking and looking.")

Maria's realization was not far with others since she said:

"Na dapat bantay gyud to the max. Dili dapat mukumpyansa hilabi na kun naa ka sa duol sa flyover, tan awon gyud pag mayo kun naa ba sakyanan padung." (You have to be vigilant, do not be too much confident specially when you are near a flyover, you should make sure to look at the approaching vehicles.")

A tuba drinking session a day energized Bill, but he realized it is safer to have their drinking session at home rather than on the side of the streets.

"Natulog man ko ato sa kalsada nganong nadasmagan pa gyud ko? ("I only felt asleep on the street, but why I was still hit?") He then came up with this conviction.

Sheer, one of the participants, verbalized her outburst on what happened to her. According to her:

"Bantay bantay lagi gyud. Kana pud mga driver hinay hinay pud kay dili baya ta mananap na walay tag iya." (We must be watchful. Drivers should drive slowly because we are not like animals that have nobody.")

Mar had someone else to blame with the accident:

"Manobela ang atong focus kun magdrive, dili mag cellphone, dili mag text text para walay disgrasya", he acclaimed. ("We should focus on the steering wheel when driving, no cellphone, no texting to stay away from accidents.")

The reality of being poor was the reason for Cindy. She said:

"Unsaon man na sa kalsada man ato panginabuhian?" ("What else can we do; the street is where we earn our living?")

Taking action restores a sense of control and directly counteracts the sense of powerlessness that is the identifying mark of trauma (McGrath, 2016). The reality of believing that pedestrian is not always the safe way is admissible to the informants. Safety is not just about being streetwise but also about choosing the right route, the right time or the right attitude when using the pedestrian. In here, the informants verbalized the root cause and shortcomings that have led them to the accident.

\section{Theme 3 "Proceed"}

After a temporary pause or interruption and gradual returning of their energy, this is the stage of finally going on in an orderly systematical manner. Life in the truest sense is an unending cycle of happiness and sadness; victory and defeat; goodness and badness; and giving up and moving on. After their agony, the informants gain the knowledge or understanding of the effect of their experienced phenomenon to their lives. Their individuals' endurance and resilience to the tides of life did not stop them from advancing and staying back to the track.

A big question crossed on Cindy's mind, the incident was fearful but circumstances forced her to continue.

"Kun muhunong tag paninda, unsa man ako ibuhi nila? Maayo unta makapangita ta ug lain trabaho nga dili diri sa kalsada kay kuyaw baya". ("If I will stop selling, how will I feed them? How I wish I could find other job because of its threats.")

Bill cheerfully stated

"Aw kining hitabua parte na gyud ni sa kinabuhi sa usa ka tawo. Aw mao nay giingun nga di matag an ang digrasya." ("This incident is indeed a part of a man's life. It is really true that tragedy cannot be predicted.") He further stated, "Mag inom pa gihapon nganong dili? Mao nay nagpaaskil nako. Pero sa balay nalang ko makig inom ug dili na maglakaw lakaw. Basin unya sa sunod deritso haybol ko ani." ("I will still continue to drink, why not? This makes me feel alive. But I will stay inside the house and will not go somewhere else. Or this might be my end.")

Just like the other respondents, Leo also had the realization that:

"Tabang gihapon kung mama sa balay. Eskwela gihapon para malingaw. Kun makakita ko ug motor, magpalayo ko kay mahadlok ko basin madasmagan na sad." "“I still help my mom with the household chores. I continue studying to entertain myself. Whenever I see a motorcycle, I stay on a distant because I am afraid, I will be hit again")

These three informants likewise shared the same 
realization as the others had. Chad said,

"Pero ga sige na pud ko bike pero lihay nako sa mga nakapark na mga sakyanan kay mag imagine man ko na naa na sad mangabri kalit" (I still continued cycling but I have to stay away from parked cars because I always imagine its door will be opened all of a sudden.)

\section{To Tetchy}

"Bisan sa disgrasya, mapasalamaton gihapon ta kay duna man sad kaayuhan nga mi emerge gikan sa negative. Basta ampo lang gyud ug amping sa kanunay para sa pamilya." ("Despite the accident, we should be always thankful because goodness always come out from negative. Just pray and always be safe for your family.")

Learning to get back to her old life was difficult for Maria but she was able to surpass her fear. According to her:

"Karon gyud tinuod maam ako na sad tighatud sa ako anak. Medyo wala na sad nahadlok ug suroy." ("The truth is, I am the one sending my daughter to school again. I am not even that scared to stroll around anymore.")

This stage sets everything firmly in place. Once this epiphany or shift in thinking occurs, the old way of thinking, feeling, reacting and behaving is over. This results in a release of old pain, thoughts or other hurts that have lingered, and one feels lighter, freer and less encumbered (Barlow 2013).

\section{Exhaustive Description}

In the crossroad of life, it gives us an opportunity to think whether we need to Pull Over, to Caution, or to Proceed. There are situations we are made to experience that will have an impact to our lives. However, there are things and circumstances which is way beyond our control. Accidents, as its name denotes, are things that occur in a man's life without having the knowledge of having it occurring at a certain time, at a certain place, and at a certain situation.

Pull over is a phase in which victims relate and relive the fear they felt instantaneously after a traumatic accident. It is something that is easily overcome. It has caused minor disruption and setbacks in their daily activities. It was difficult for them to resume with the usual day-to-day activities; thus, they seek for refuge and comfort. Fear, anxiety, depression, melancholy, and generalized weakness are some of the manifestations that they felt that hindered them from resuming to a normal life. Being in such a situation poses a great challenge to the lives of these individuals. Indeed, life stops us if we think that we need to recalibrate our lives to certain occurrence of events.

Caution is a phase of transition; where there is eventual resumption of strength and confidence to be back on one's feet. A person who has gone through accidents need to dwell on that condition forever. One must strive to go back to a life that they have lived before the uneventful experience. Gradually, the victim went back to the streets but with much caution and safety, and with the assistance of their beloved significant others. As one take one step at a time, it directs him to be more focused in living a normal life, choosing the right path, at the right time, and with the right attitude and becomes a much more responsible pedestrian.

Proceed is the phase of moving on. Whatever one experiences in life that may have deterrent effects does not make person totally invalid. A person is a made to experience things in life to learn, to become a better individual. Although there are some unforeseen circumstances that poses a bad effect on a person's life, yet, it does not make him a miserable one for his entire life. This is the "Green" sign on the traffic light which means "GO". The respondents at this point are having full control of their own lives and have full desensitized themselves to the event. Indeed, accidents are not your everyday friend; they come to you when you least expect them. It is inevitable, disastrous, life-changing, goal breaking, but they are not meant to put life in eternal misery. There comes a point in time where one makes a realization that life is what you make it, and that there are challenges that needs to be fought back and there are battles that need to be finished. Life is a risk that is worth taking. A bad event might happen, but life also gives us the most beautiful memories that will help us to shape life at its fullest.

\section{CONCLUSION}

In the light of the results of this study, the physical injuries are not enough to determine the intensity of a trauma. Often, the psychological trauma had rather more profound impact on their lives and the mental disequilibrium. Despite the divergence of the characteristics in each of the informants, majority if not all, have gone through the same process of fear resulting from the injury and experienced abrupt withdrawal from the usual daily routines, gradual return with caution and 
the stage of finally moving on with confidence.

\section{Recommendation}

Nurses, as the catalyst of change must work in parallel with other healthcare providers to formulate a holistic approach in taking care of victims of vehicular accidents, specially the pedestrians. A customized nursing approach tailored to their individual needs must be utilized rather than focusing on a single aspect of their injury. This research will hopefully be used as basis of revising the existing protocol on the type of patients admissible in the Women and Child Protection Center (WCPC) because pedestrian victims need psychological debriefing and reevaluation more often. The Quality Management System in each health institution should ensure that this protocol be strictly followed by nurses, doctors and other medical allied professionals so that a favorable result that would not only benefit the hospital but the community and the victim as well, would be at hand.

Also, in line of the research study, future researchers should explore more meaningful experiences not just from the victims themselves but also from their families and the significant others that might be also used to develop a useful and effective tool in alleviating one's psychological imbalance. Furthermore, it is also imperative that community programs and follow ups be made available to these victims to ensure continuity of care.

The Philippine government had crafted several traffic laws and policies for the sole purpose of minimizing if not totally eradicating road crash fatalities and injuries. However, with the increasing number of motor vehicular accidents (MVA) everyday, these measures noticeably failed. Nurses as advocates to the patients and as educators, must also conduct outreach programs and community-based teachings that would include proper usage of pedestrians, existing traffic rules and road safety. Though taking part in reshaping the driver's mindset is very crucial and skeptic at times, this should not be the hindrance in attaining a positive result.

\section{Conflict of Interests}

The authors declare that they have no conflict of interest.

\section{ACKNOWLEDGEMENT}

The authors are thankful to the institutional authority for completion of the work.

\section{REFERENCES}

Adams, N. Fleisher, C. \& Winston F. (2009). Acute stress disorder and posttraumatic stress disorder in parents of injured children. Journal of Traumatic Stress, 22(4), pp 294-302.

Alnaqbi, K., Saleh, W., Cullinane, K. \& Kermani, A. (2013). Pedestrian right-of-way violations at signalised pedestrian crossings in Edinburgh. Edinburgh Napier University. Retrieved from: https://www.napier.ac.uk/research-andinnovation/research-search/phds/pedestrian-rightofway-violations-at-signalised-pedestrian-crossings-inedinburgh

Balls, P. (2009). Phenomenology in nursing research: methodology, interviewing and transcribing. Nursing Times, 105(32-33), pp 30-33.

Barlow, S. (2013). The Five Stages of Emotional Healing. Crossing Over from Pain to Peace: Thresholds. Retrieved from: https://susannabarlow.com/healing/the-five-stages-of-emotional-healing/

Berry, L. (2013). The 5 Stages of Healing from Trauma. Licia Berry: The Guide to the Frontier of Inside. Retrieved from: https://liciaberry.com/2013/02/18/the-5-stages-of-healing/

Centers for Disease Control and Prevention (CDC) (2017). Pedestrian Safety, Motor Vehicle Safety (2017). Retrieved from: https://www.cdc.gov/motorvehiclesafety/pedestrian_safety/index.html

Choosegros, L., Hours M., Charnay, P., Bernard, M. Fort, E. Boisson, D., Sancho, P., Yao, S. \& Lauman, B. (2011). Predictive factors of chronic post-traumatic stress disorder 6 months after a road traffic accident. Accident; Analysis \& Prevention, 43(1), pp 471-477.

Christensen, M., Welch, A. \& Barr, J. (2017). Husserlian Descriptive Phenomenology: A review of intentionality, reduction and the natural attitude. Journal of Nursing Education and Practice, 7(8), pp 113-118. 
Crossman, A. (2017). Understanding Purposive Sampling: An overview of the method and its application. Retrieved from: https://www.thoughtco.com/purposive-sampling-3026727 Department of Health (2013). Retrieved from: http://portal.doh.gov.ph/vehicular_accidents.htm

Galovski, T. \& Veazey, C. (2016). Surviving the Crash: Stress Reactions of Motor Vehicle Accidents. PTSD Resources for Survivors and Caregivers. Retrieved from: http://www.giftfromwithin.org/pdf/crash.pdf.

Grbich, C. (2013). Qualitative data analysis: An introduction. London: Sage Publications Inc.

Hui, Zhiyong, Y., Rong, C., Huipeng, C., Cui, S., Guanyu, Y. \& Zhenggou, W. (2010). Investigation of 184 passeger car-pedestrian accidents. International Journal for Crashworthiness Journal, 15(3), pp 313-320.

Landot, M., Vollrath,M.,Gnahem, H. \& Sennhauser, F. (2009). Post-Traumatic Stress Impacts on Quality of Life in Children After Road Traffic Accidents: Prospective Study. Australian \& New Zealand Journal of Psychiatry, 43(8), pp 746-753.

Lopez, K.A. \& Willis, D.G. (2004). Descriptive versus interpretive phenomenology: Their contribution to nursing knowledge. Quality Health Research, 14(5), pp 726-35.

McGrath, E. (2016). Recovering from Trauma. Psychology Today. Retrieved from: https://www.psychologytoday. com/articles/200111/recovering-trauma.

Merriam Webster Dictionary (2017). Retrieved from: https://www.merriam-webster.com/words-at-play/new-words-inthe-dictionary-feb-2017

Murgatroyd, D.F., Cameron, I.D. \& Harris, I.A. (2011). Understanding the effect of compensation on recovery from severe motor vehicle crash injuries: a qualitative study. Injury Prevention, 17(4), pp 222-227.

Olofsson, E., Bunketorp, O. \& Andersson, A.L. (2008). Children and adolescents injured in traffic - associated psychological consequences: a literature review. Acta Paediatrica, 98(1), pp 17-22.

O’Reilly, M. \& Parker, N. (2012). Unsatisfactory saturation: A critical exploration of the notion of saturated sample sizes in qualitative research. Qualitative Research, 13(2), pp 190-197.

Shosha, G. (2012). Employment of Collaizi's Strategy in Descriptive Phenomenology: A Reflection of a Researchers. Retrieved from: https://eujournal.org/index.php/esj/article/viewFile/588/657

Speziale, H.J. \& Carpenter, D.R. (2007). Qualitative Research in Nursing: Advancing the humanistic imperative. (4 ${ }^{\text {th }}$ ed.). Philadelphia: Lippincott, Wilimans and Wilkins.

Tufford, L. \& Newman, P. (2010). Bracketing in Qualitative Research. Qualitative Social Work, 11(1), pp 80-96.

Tull, M. (2016). The Risk of PTSD After a Car Accident. Verywell mind. Retrieved from: https://www.verywellmind. com/risk-factors-for-ptsd-following-a-traffic-accident-2797197

Walker, J. L. (2012). The use of saturation in qualitative research. Canadian Journal of Cardiovascular Nursing. 22(2), pp 37-46.

World Health Organization (2015). Global Status Report on Globe Safety. Retrieved from: http://www.who. int/violence_injury_prevention/road_safety_status/2015/en/

Yutaka, M., Daisuke, N., Satomi, N., Kim, Y., Homma, M. \& Otomo, Y. (2008). Incidence and prediction of psychiatric morbidity after a motor vehicle accident in Japan: the Tachikawa Cohort of Motor Vehicle Accident Study. Critical Care Medicine, 36(1), pp 74-80.

Zehnder, D., Meuli, M. \& Landolt, M.A. (2010). Effectiveness of a single-session early psychological intervention for children after road traffic accidents: a randomised controlled trial. Child and Adolescence Psychiatry and Mental Health, 4:7. 